\title{
The role of public agencies in blockchain consortia: Learning from the Cardossier
}

\author{
Schwabe, Gerhard
}

\begin{abstract}
Blockchain technologies enable new forms of data sharing in platforms. This raises questions around how they are jointly developed and managed in blockchain consortia and what role public agencies play in those efforts. Based on an analysis of prior work on data sharing in public-private partnerships and other blockchain projects, we analyze the case of the Cardossier. The Cardossier project and (later) association develops a platform to link the public and private actors in the Swiss car ecosystem. The participating car registration authority has the roles of an actor in interorganizational processes, supplier of data, source of trust, guarantor of data quality, user of data, and incentive for making goods public. We conclude that the public agencies have a very important role in blockchain consortia and propose that they should use this role actively as part of their efforts to create public value.
\end{abstract}

DOI: https://doi.org/10.3233/IP-190147

Posted at the Zurich Open Repository and Archive, University of Zurich ZORA URL: https://doi.org/10.5167/uzh-177086

Journal Article

Accepted Version

Originally published at:

Schwabe, Gerhard (2019). The role of public agencies in blockchain consortia: Learning from the Cardossier. Information Polity, 24(4):437-451.

DOI: https://doi.org/10.3233/IP-190147 


\title{
The Role of Public Agencies in Blockchain Consortia:
}

\section{Learning from the Cardossier ${ }^{1}$}

\author{
Gerhard Schwabe \\ University of Zurich \\ Institute for Informatics \\ Binzmühlestrasse 14 \\ CH-8050 Zürich \\ Tel: +41-44-63-5 4305 \\ Fax: +41-44-63-5 6809 \\ schwabe@ifi.uzh.ch
}

\begin{abstract}
:
Blockchain technologies enable new forms of data sharing in platforms. This raises questions around how they are jointly developed and managed in blockchain consortia and what role public agencies play in those efforts. Based on an analysis of prior work

\footnotetext{
${ }^{1}$ The final publication is available at IOS Press through http://dx.doi.org/ 10.3233/IP-190147
} 
on data sharing in public-private partnerships and other blockchain projects, we analyze the case of the Cardossier. The Cardossier project and (later) association develops a platform to link the public and private actors in the Swiss car ecosystem. The participating car registration authority has the roles of an actor in interorganizational processes, supplier of data, source of trust, guarantor of data quality, user of data, and incentive for making goods public. We conclude that the public agencies have a very important role in blockchain consortia and propose that they should use this role actively as part of their efforts to create public value.

\section{Key points for practitioners:}

- Blockchain platforms enable new forms of data sharing between public and private organizations. These platforms are typically created by consortia facing governance issues.

- Public agencies play an important role in those platforms as an actor in interorganizational processes, supplier of data, source of trust, guarantor of data quality, user of data, and incentive for making goods public.

- The car ecosystem is a promising area for creating blockchain platforms.

Keywords: blockchain platform, blockchain consortium, blockchain governance, publicprivate partnerships, data collaboratives, car ecosystem, road traffic authority 


\section{Introduction}

Blockchain technologies have moved on beyond cryptocurrencies. An increasing number of organizations experiment with how to make best use of blockchain technologies for improving their collaboration and joint value generation. They team up in 'blockchain consortia', trying out what is possible to achieve together. There have been efforts to reorganize land-registers (Themistocleous 2018), public health (Gordon \& Catalini 2018), student certificates (Gräther et al. 2018), and the used car market (Notheisen et al. 2017). One important common feature of those blockchain consortia appears to be the prominent role of public agencies. While this is obvious in cases, where public registers are replaced or augmented, it is less obvious in other cases, e.g. in the used car market. So, what exactly is the role of public agencies in blockchain consortia? Are they key players or just "nice-to-have"? How does the presence of public agencies influence the governance of blockchain consortia?

This paper will explore the role of public agencies using the case of the Cardossier project. The Cardossier project strives to improve the Swiss car ecosystem by storing and sharing data from the life cycle of a car (import, registration, repair, insurance, accidents, driving behavior, etc.) in a blockchain. The authors have engaged as scholars (Mathiassen \& Nielsen 2008) in this undertaking and report from a rich basis of data and experiences. The case description and the subsequent analysis will be useful for setting up and governing blockchain consortia that develop platforms for the used car market and beyond. It will inform public agencies' choices regarding the opportunities and challenges of blockchain-based collaborative value generation when entering blockchain consortia (Bauer et al. 2019). It should also educate blockchain startups and 
help them understand what it means to collaborate with public agencies. Researchers will gain insights into a fascinating new topic: Blockchain governance in the presence of public agencies. We call for revisiting the literature on public-private partnerships in light of the new technological opportunities.

This paper will first introduce related work. In doing so, we will briefly review the literature on public-private partnerships and data collaboratives, on blockchain technologies, and on blockchain consortia; we will then turn to the literature for case descriptions for blockchain consortia that involve public agencies. The second section will present the methodology and the data collection. In the third section, we will describe the Cardossier case as it evolved over time, with a particular focus on the role of the car registration authority. The case will then be discussed in the light of prior knowledge of the role of public agencies. Conclusions and limitations will finish the paper.

\section{Public Agencies in Blockchain Consortia}

\subsection{Public-private Partnerships and Data Cooperatives}

The Bible offers the first evidence of public private partnerships, for the purpose of collecting taxes' (Hodge \& Greve 2007). Most recent public private partnerships projects address infrastructure such as highways or power networks (Hughes 1993), but there is also a history of public-private Partnerships for information systems. In publicprivate Partnerships, public agencies enter into long-term relationships with private organizations based on an incomplete contract (Hart 2003). In infrastructure projects, the main driver is sharing the financial burden of an investment, either because funds 
are limited or because lower costs increase its political acceptance. The incomplete contract triggers the need for some organizational arrangement, which can assume a tight or loose form (Hodge \& Greve 2007). Infrastructure projects also dominate the debate in the IT-sector, e.g., building up a high-speed-internet infrastructure and general initiatives to advance digitalization and digital skills in an economy. The incomplete contracts frequently lead to frustrations that are best summarized by Dieter Klumpp, condensing his decades of experience in PPP as head of the Alcatel Lucent Foundation in the sentence: "Oh, I thought YOU would pay!" (personal conversation).

In recent years, a new form of PPP has arisen around the notion of sharing data: Public and private agencies create platforms to exchange or share data. Government agencies may engage in those platforms just to improve operational efficiencies. Or they engage with private organizations in 'data collaboratives' (Klievink et al. 2018; Verhulst \& Sangokoya 2015) or 'data driven social partnerships' (Susha et al. 2018) to jointly create value, typically in a collaborative innovation addressing a societal challenge. Or they invest in shared platforms to transform the government 'outside-in' (Klievink et al. 2016). In all cases there are differences of interests and tensions between participating organizations, and therefore there is a need for a network governance (Klievink et al. 2018). Decision rights and rules are needed to steer the whole platform while leaving sufficient autonomy to the actors to create value for their own purposes. Ownership over platforms must be established and if it is a shared platform, neutrality needs to be assured. Typically, the platform offers access to shared data as incentive to participate. This can lead to very mundane benefits, such as less burdensome reporting (Klievink et al. 2016), joint supply chain management (Klievink et al. 2016), or even joint innovation 
(Klievink et al. 2018). It is particularly important to incentivize the data providers (Susha et al. 2018). Here, typical reimbursement mechanisms are currently still based on barter, e.g., the government agencies can provide aggregated analysis in return for access to the primary data from private organizations (Klievink et al. 2016). There are further issues for consortia engaged in such partnerships (Susha et al. 2018) in the areas of regulation (e.g., lack of consistent and comprehensive legal provisions), organization (e.g., difficulties in collaboration, lack of finance or lack of trust), data (e.g., data privacy, data security and data quality), and society (e.g., institutional and political power shifts).

Sharing a data platform frequently leads to conflicts between private partners. Here, government agencies may serve as a neutral actor to create a fair environment and facilitate conflict resolution (Susha et al. 2018). On the other hand, public agencies have to guarantee public interests and are a substantial provider of data. This triple role as neutral actor, guarantor of public interest, and data provider frequently gives public agencies a leading role in collaboratives (Klievink et al. 2018). Thus, there is ample literature on opportunities and challenges in private public partnerships where partners team up to create physical infrastructures. There have been some efforts to transfer and instantiate these insights to data infrastructures. However, these efforts came before the advent of blockchain platforms. Does the opportunity to assure distributed trust (Auinger \& Riedl 2018) and exchange value digitally (Truong et al. 2018) offer new opportunities and pose new challenges? 


\subsection{Blockchain, Blockchain Platforms and Blockchain Consortia}

From a user perspective, blockchain technologies provide a shared database with some unique features. The database is implemented as a distributed ledger which allows decentralized control over data items and the database as a whole ( $\varnothing$ Ines et al. 2017). Due to cryptographic algorithms, the data entries are (almost) immutable. This allows unique data items in a distributed setting. These unique data items can be used to authenticate transactions (e.g., a land transfer transaction using a distributed land registration ledger (Themistocleous 2018)). These transactions can be conducted without the need for trusted intermediaries (Tapscott \& Tapscott 2016) and may ultimately lead to a more distributed government and governance ( $\varnothing$ Ines et al. 2017). Blockchain technologies also introduce 'digital scarcity' (Miscione et al. 2018). The initial use case for digital scarcity is digital money: digital bills only have value if they cannot be copied. Now, there are a range of other use cases for storing value (Tapscott \& Tapscott 2016), including titles of ownership or usage rights (e.g., of electricity (Albrecht et al. 2018)). Blockchain technologies have rapidly evolved from data storage (first generation) to blockchains that are programmable with "smart contracts" (second generation), to advanced distributed ledgers, forfeiting immutability solely guaranteed by technology in exchange for better performance and scalability as well as reduced electricity consumption. These distributed ledgers are frequently 'permissioned', i.e., they are not accessible to the anonymous public anymore but rather require identification of the users. Use of such permissioned blockchains is a prerequisite to place the systems under the rule of law, i.e., to allow the platform providers to use the legal system, run the platform, and to force the platform providers to stay within the limits of legal regulations. 
Blockchain platforms are an important application area of blockchain technologies. On these platforms, different actors meet to exchange information and value (Kenney \& Zysman 2016). Since the rise of Google, Amazon, and Facebook, platform ownership has proven to be a source of tremendous economic and social power. Blockchain platforms can be used to distribute this power amongst all participants: Participants can all keep ownership of the data they provide and decentrally authenticate transactions among them. Furthermore, they have the capability to store and distribute value digitally. This allows the management of digital assets (digital money, titles, etc.) and the use of digital "tokens" (Oliveira et al. 2018) to incentivize a desired behavior. For example, the Steem social media platform offers Steem tokens in exchange for the contribution of useful content (Ciriello et al. 2018). Blockchain platforms require the active participation of diverse actors of the ecosystem and are therefore frequently created by 'blockchain consortia' instead of being created by startup companies. Blockchain consortia operate in a similar manner to consortia creating physical infrastructures or digital infrastructures (see above). However, they have the opportunity to use blockchain technologies not only for the delivery of the platform itself but also for organizing their collaboration and, most importantly, their governance (Beck et al. 2018, Ziolkowski et al. 2018). While the extreme form of a "distributed autonomous organization" run purely by smart contracts turned out to be an expensive illusion, specialized blockchain applications can automatically distribute tasks and support decision making by voting. The increased automation of governance requires more careful planning of blockchain consortia when compared to conventional consortia planning (Miscione et al. 2019). Furthermore, the automation of contracts and the transfer of values raise important 
legal and regulatory questions, most fundamentally whether a 'smart contract' is a legally binding contract and whether there can really be ownership of data.

The new capabilities of blockchain technologies in general, and blockchain platforms in particular, have attracted interest from public agencies and they have started experimenting with blockchains ( $\varnothing$ Ines et all. 2017). They have joined a number of blockchain consortia asking themselves: Can blockchain platforms solve some of the problems public-private partnerships have been struggling with in the past?

\subsection{Public Agencies in Blockchain Consortia}

Experimentation with blockchain technologies has led to a series of small projects with the engagement of public agencies ${ }^{2}$. Land registries, Certification of University degrees, and Health records are the most prominent use cases.

a) Land registries: Ghana, Sweden, Honduras, and Georgia have all experimented with placing land registries on the blockchain (Themistocleous 2018; Benbunan-Fich \& Castellanos 2018). While in Western countries the case for blockchain-based registries focuses more on the operational efficiency of processes, the case for developing countries is more fundamental: In Ghana and Honduras, land registries have not been established like they have in developed countries, and the inhabitants do not trust the government. The resulting insecure land ownership seriously hampers their economic development. In addition, in Georgia the authorities are afraid of what would happen to

\footnotetext{
2 An overview over the of projects of very active Dutch public administration can be found under https://www.blockchainpilots.nl
} 
their land registers in case of occupation. In all cases, the blockchain consortia are dominated by the public agencies: They decide how the technology of the platform is further developed, they authenticate data, and they decide on who is entitled to membership of the consortium running the platform. Regular courts settle disputes of ownership or transactions. In all cases blockchain technologies are used to link the different partners to a shared platform and to authenticate central information. Most of the actual information is still stored in conventional databases because they perform better, because they store data far more cheaply, and because current blockchain technologies may be replaced by superior technologies in the near future. Yet, due to the ability to store authenticated immutable records, land registries are among the most promising and farthest developed blockchain platforms. The first research reports on their governance have just being published (Miscione et al. 2018; Ziolkowski et al. 2019).

b) Certification of University degrees: University degrees are important parts of citizens' CVs. Currently, they are only available in paper form, leading to both inefficient processes and frequent fraud. Thus, there have been efforts to create a distributed digital certification platform (Schmidt 2015; Gräther et al. 2018). While in the case of land registries one public agency could establish a clear leadership role, many universities have to collaborate to jointly create and run this platform. Furthermore, private organizations are also important stakeholders as they are the primary users of the certificates when hiring university graduates. Currently, there are ample proof of concept prototypes and pilots running, but none have yet reached the stage where a significant number of stakeholders are collaborating. Thus, it is too early to evaluate the role of public agencies in the consortia developing them. 
c) Health Records: The health ecosystem consists (at minimum) of patients, doctors, other healthcare professionals, pharmacies, hospitals, public regulators, and health insurers. Core to most digital transformation efforts is a digital patient record, containing the patient's personal information and their health history. Lengthy disputes over who owns this patient record has significantly hampered the ecosystem-wide adoption of digital health records so far. Here, blockchain platforms offer the opportunity to distribute data ownership and access as well as platform decision making. There have been experiments addressing the interoperability, removing intermediaries, enabling more patient centric treatments and giving patients more control (Gordon \& Catalini 2018) by a blockchain. Access to health data is granted liberally to qualified persons, but all such access to health data is tracked, so it can be challenged if necessary. Specific research on the role of the public agencies in this sector does not yet exist.

Furthermore, blockchain platforms have been used to provide refugees with digital identities (Fridgen 2018), to distribute cash-based aid (Zwitter \& Boisse-Despiaux 2018), and to improve the academic publishing process (Novotny et al. 2018). The case of the car ecosystem has also been addressed before, elaborating on use cases (Notheisen et al. 2017), addressing privacy-preserving IOT data collection (Chanson et al. 2019), discussing opportunities for business models (Bauer et al. 2019), analyzing the incentive systems (Zavolokina et al. 2018), selecting appropriate tokens (Oliveira et al. 2018), designing a data market (Bauer et al. 2019), and addressing trust issues (Zavolokina 2019). However, none of these publications have addressed the governance of 
blockchain consortia and the role of the public sector. There is furthermore a continuous stream of announcements and whitepapers from industry (e.g. from Hyundai ${ }^{3}$ ) or the public sector (e.g. the government of Bahrain ${ }^{4}$ and the city of Seoul ${ }^{5}$ ), but again without an in-depth discussion of the role of the public sector and blockchain governance.

In summary, we conclude from this literature review that there is ample literature on general public-private data sharing through platforms. It typically focuses on 'public value' use cases and provides important insights on the regulatory, organizational, data handling, and social issues of data sharing. Are those insights applicable to blockchain consortia and do they sufficiently describe them? Reports on blockchain consortia and platform development are so scarce, that it is worthy of further exploration.

\section{Methodology and Data Collection}

The Cardossier Project followed the approach of solution-based probing (Briggs et al. 2019), i.e., the idea for a technological solution is the starting point. In a continuous process of developing and testing (partial) solutions, both an understanding of the problems and the potential for technology to create a solution develops. In many ways, solution-based probing is a subclass of action design research (Sein et al. 2011): Research switches between phases of engagement and reflection. Engagement phases

\footnotetext{
3 https://medium.com/aergo/hyundai-autoever-presents-blockchain-based-used-car-trading-service-atposco-tower-mentions-aergo-1f485521325

${ }^{4}$ https://www.coinwelt.de/2018/05/bahrain-registrierung-von-autos-mit-der-blockchain/

${ }^{5}$ https://news.itu.int/seoul-blockchain/
} 
cover not only organizational work, but also the design of prototypes. And this project covers the last research mile (Nunamaker et al. 2015), going from proof-of-concept research over proof-of-value research to proof-of-use research.

Data on the Cardossier was collected on different occasions. As part of an in-depth stakeholder and business analysis, the role the car registration authority plays in the ecosystem was explored in several interviews and workshops. Theses interviews were transcribed and coded using MAXQDA. Researchers analyzed the processes and the data flows between the car registration authority and other partners in the car ecosystem. The most important insights were gained through the ongoing discussions in the triweekly project meetings and the quarterly steering committee meetings. Minutes were taken at the steering committee meetings, but it was not possible to systematically capture all relevant discussions. Therefore, we conducted a post-hoc validation of the reported results, during which involved the actors (the project manager, the manager in charge from the car registration authority, and three participants from the project team) checked the described results and subsequent discussion for correctness.

\section{Results}

\subsection{Introduction to the Cardossier Project}

The Cardossier project aims to improve the Swiss car ecosystem by storing car usage data in a blockchain. There are three major areas for improvement (Bauer et al. 2019):

1. New product offerings, like documented car histories, could potentially increase the transparency of the used car market and thus increase the value of cars in the "market for lemons" (Akerlof 1978), 
2. Digitization of processes between the actors in the car ecosystem could increase its operational excellence, and

3. Better customized products and services could be based on Cardossier Data (e.g., new insurance products or peer-to-peer car lending).

This requires storing the history of car usage starting with the import and ending with the wrecking of the car. In between, all major events need to be covered, e.g., registrations, repairs or inspections, insurance contracts, accidents, changes of ownership or obligatory car inspections by the registration authorities. Modern cars provide interfaces to extract more fine-grained technical data on car usage, e.g., how the car was accelerated or how the brakes where used. This can be aggregated to usage profiles indicating whether the car has been mostly driven in cities, in rural areas or on highways and what kind of a driver the owner was.

Owning a platform and collecting all this data is the dream of any stakeholder in the car ecosystem (particularly the car manufacturers) and many startup companies. However, the experiences with other such platforms, such as Facebook, Google, Amazon, and Uber, has warned the participants to never allow this concentration of power to happen in the car ecosystem. Most importantly, car insurance companies have warned that in any case of an accident involving a self-driving car, the car's manufacturer should not control the data that is critical to judging their level of responsibility. As public authorities are also not suited to running such a platform, a centralized solution is not an option, and a joint effort is the only option. Blockchain technologies offer the opportunity to jointly create and operate a distributed, but shared, platform for trusted car data in a more sophisticated manner than with traditional IT. 


\subsection{The Consortium Forming Phase}

The Cardossier idea was conceived by the University of Zurich and AdNovum Informatik $A G$, a medium-sized software engineering company in Zurich, Switzerland. Both partners aimed to explore the technical and business potential of blockchain technologies. Once they had settled on the use case of the Cardossier, they focused on creating a consortium with all major players in the car ecosystem on board. These were a large car importer, a car retailer, a repair shop (all roles fulfilled by AMAG, the largest Swiss car importer and retailer) and a large insurance company (AXA Winterthur, the largest Swiss car insurer). Mobility, the largest Swiss car sharing company joined, promising to deliver detailed car usage data for their cars. In addition, the car registration authority of the Swiss canton of Aargau joined (informally, for legal reasons). They are responsible both for registering cars after each change of ownership, passing on registration data to the tax authorities and for the mandatory inspection of cars every couple of years. They own important data and participate in key processes all partners are interested in, such as registering a car. Furthermore, they are a source of trust for car owners and other actors of the car ecosystem. Last, but not least, the University of Applied Sciences in Luzern joined, contributing their expertise in data protection. The consortium agreed on a project proposal, an agile development approach and project governance with formal roles for project leadership, scientific leadership, and a steering committee typical for IT innovation projects. The project was supported by a grant from Innosuisse, the Swiss Innovation Agency.

\subsection{The Exploration Phase}

The first year of the Cardossier project was characterized by exploration. The technical exploration activities focused on building a generic distributed platform for data capture 
and distribution, supporting a few basic use cases (particularly the sale of a car). Early on, it was decided to base the Cardossier platform on a permissioned blockchain. After nine months, the basic platform had to be moved from the Hyperledger blockchain platform to the Corda Distributed Ledger, because Corda provided better scalability and data protection (while giving up some key features of traditional blockchains). User requirements where validated with the Cardossier game simulating a used car market platform, and exploratory studies on user preferences and trust were conducted.

It was clear from the beginning of the project that setting up appropriate governance was a key challenge for the Cardossier project. Any permissioned blockchain has to function within a given legal system - in this case, the Swiss legal system. Thus, the future Cardossier consortium had to become a legal entity, be it a stock corporation, a cooperative or an association. All possible models were explored in great detail. Within the models, we checked for the applicability of blockchain-based decision models, based on voting and smart contracts. Decisions ranged from funding of development efforts to decisions on the business model (see below), and to entering and leaving the consortium.

As the initial funding lasted for only 18 months, crafting an appropriate business model for the time afterwards was paramount (Bauer et al. 2019). How could a platform benefit from the increased car value? How could it benefit from the efficiency gains of inter-organizational digital processes? And how could it benefit from new products enabled by Cardossier data? For all three questions, an answer was to be found in the creation of a data market. A data market can greatly benefit from blockchain, as data 
ownership is clear (within the limits of current law) for any given time. Thus, a business model could be to create and provide a comprehensive Cardossier for each car sale transaction and charge either the seller or the buyer a fee for using it. The platform could also tax any transfer of data between partners, be it for operational purposes or for new products. In Switzerland, such a data market is only acceptable if the car owners have a say on the release of their private data under a self-sovereign identity scheme (Abraham 2017).

A Cardossier data market only works, if the data is of sufficient quality (i.e., correct, up to date and complete (Zavolokina et al. 2018)). Initially, the car importer can guarantee data quality. But once a car is sold and thus released into the wild, data quality depends on many actors and not all may be reliable. While it is in the interests of all actors to include sales transactions, insurance details and records of mandatory inspections into each Cardossier, accidents may be a different story. Any serious accident decreases the value of a car significantly and thus there is an incentive for a car owner to bribe a repair shop into repairing the car without an entry into Cardossier. The blockchain provides a first safeguard as it can prove at any later time what events, such as accidents, were reported in relation to a particular car at any given time. So, a buyer can later prove that an accident has not been reported to him. Reputation mechanisms for car repair shops and other actors in the ecosystem and a whistleblower mechanism may provide an incentive to all stakeholders to provide complete and correct data (Zavolokina et al. 2018). Some data fraud may also be prevented by insurance companies insisting on an entry into the Cardossier by participating car owners. However, the most important incentive can be provided by the car registration authorities: Currently, Swiss car 
registration authorities do not only register cars, but also perform mandatory inspections in their workshops. It is clear that with the increasing digitalization of cars and the move towards electric cars, the authorities have less to inspect: The mechanics of electric cars are simpler, and the authorities do not have the means to inspect software that is specific to each brand. So, their traditional business model is likely to be obsolete in the coming years. In the future, they will have to rely on data provided by the car itself and by data provided by other actors in the ecosystem. A complete, correct and up-to-date Cardossier will allow for a digital checkup most of the time. If the car registration authorities go this way, they will insist on a Cardossier that is complete for all data they need. And as a state agency, they can provide a strong incentive as incomplete data may be considered as fraud.

A last stream of exploration addressed possible use cases for 'CarCoins' (i.e., digital tokens representing something of value (Oliveira et al. 2018)). Should a CarCoin represent a car? Should CarCoins be used for paying for data (allowing for paying even fractions of a cent) and internal taxation in the data market? Should CarCoins be generated to pay for validation (by 'notary nodes' in Corda) and generally running the platform? Should they give voting power in a Cardossier platform? Should they provide an incentive for data provision to the platform? Or should CarCoins represent shares of a future cooperation (or similar construction)? This exploration phase culminated in different options for continuing the Cardossier project: Should it aggressively ride the Initial Coin Offering wave like most other projects addressing the car ecosystems at that time (most of these projects disappeared after a year)? This would transform the consortium into a company and could raise a double-digit million-dollar amount of initial 
funding, assuring the operations for the Cardossier for several years. Or should it continue on its path as a consortium providing a shared platform?

\subsection{Preparing Market Entry: The Consolidation and Ramp-up Phase}

The consolidation phase started in Autumn 2018 and it was about making choices. The consortium forfeited the opportunity to raise money in an ICO and rather decided to found a non-profit association open to all Swiss stakeholders (including car owners). A senior manager from the Aargau car registration authority took over the task of founding the association and was elected president of the Cardossier Association. Six further Swiss companies, including a major financial service provider, joined the association in March 2019 and contributed their share for the development efforts until the Go-live in 2020.

The decision to hand over the presidency to the car registration authority was grounded in the nature of the Cardossier platform. The platform is a network product and it is only valuable if it covers a large part of the Swiss car ecosystem; in many senses it thus resembles a network product. The car registration authorities are an indispensable part of this ecosystem: They not only participate in core processes, but also provide access to other public agencies, influence regulations and are widely trusted by Swiss citizens. But this trust comes with a 'cost': According to the Swiss understanding of the role of government, they should only participate in the ecosystem if the platform is non-profit and open to all Swiss stakeholders. This basic setup limits the options for governance and a data market. It is still possible to automate some decision making through voting and smart contracts and it also allows for some tokens. However, regarding tokens the 
regulation in Switzerland is still in flux and banks entering the consortium will push the topic ahead.

The Cardossier Association governs and develops the basic Cardossier platform and the data exchange between partners. As typical for modern platforms, the Cardossier is split into a core and extensions. The core covers the basic business logic for the Cardossier platform and the data market, like access and permission rights. It also structures how the different stakeholders interact with each other and are governed in this shared network: Last, but not least it provides infrastructure and logic for data market. On top of the core platform there are DApps ("Decentralized Applications" following the example of Ethereum ${ }^{6}$ ) for the individual use cases such as a car import, fleet management, or car sales. These DApps will be developed by subgroups of the association and they can be for-profit. Thus, the Cardossier Association provides a blockchain-based multi-sided platform, connecting the major private and public players in the car ecosystem, software-companies, and private car-owners.

The business case for all partners depends on the availability of sufficient data. Ramping up an initial data set of basic car data for a large fraction of Swiss cars is key to get all other activities running. On the one hand, this turned out to be surprisingly easy as the data exists with several stakeholders. On the other hand, data quality turned out to be an issue for many stakeholders, not least for the public agencies on a canton and federal level. Some fields (e.g., the initial purchase price) turned out to be wrong in up to 40

\footnotetext{
${ }^{6}$ https://ethereum.stackexchange.com/questions/383/what-is-a-dapp
} 
percent of all car records, because this information is entered manually by the actors based on unreliable sources (i.e., the car owner). So, members of the consortium do not only save the effort of manual data entry by exchanging data, but also have more accurate data if they receive it from reliable sources. However, understandably the sources of reliable data want to be rewarded for their efforts. Thus, the consortium currently aspires to design a data market that provides incentives, transparency and a fair exchange mechanism for different kinds of data products.

\section{Discussion}

Blockchain Consortia strive to improve collaborative value generation based on a shared, but distributed platform. They typically work within a 'society', i.e., they have to accept social norms, legal rules, and regulations. In these consortia there is a place for public agencies. So, what exactly is the role of public agencies in blockchain consortia? As we can see from the Cardossier case, they play an important role in interorganizational processes as a supplier of data, a source of trust, a guarantor of data quality, a user of data, and an incentive for making goods public.

a) Actor in interorganizational processes: In a developed country, almost all interorganizational processes involve some public agency collecting tax, regulating activities, or providing its own services. In widespread high-value-high-risk areas, such as land ownership or car usage, the role of governments is particularly strong. They do not just oversee the actors but also get involved in the most important transactions themselves, e.g., property sales transactions or assuring roadworthiness of cars. In this role, they have a primary interest in efficient and effective (meaning digital) processes. 
Blockchain technologies facilitate orchestrating those interorganizational processes without a powerful central private actor and also without state agencies transgressing their traditional boundaries of responsibilities. The Cardossier case furthermore shows the transformational power of shared distributed platforms (enabled by blockchain technologies) for government agencies. The car registration authorities are enabled to switch from a hands-on checking of cars to digital checking of car fitness. The hands-on inspection of vehicles is no longer required at a government agency level and can be delegated to private garages (and to the car manufacturers for software provision). So, it is not just 'transformation outside-in' of a public agency (Klievink et al. 2016) but 'transformation inside-and-outside' in collaboration with private and public partners to jointly reshape an ecosystem.

b) Supplier of data: Registries are primary candidates for blockchain applications: Persistent and unchanged records and transactions are at the heart of any register. As in other cases (e.g., land registers), existing registers are valuable hubs of trustworthy information. After all, only the government has a complete register of all Swiss cars allowed on the roads. This includes all safety-relevant parts that can be used in those cars (e.g., different sets of wheels). Setting up this harmonized central register has cost a double-digit million-dollar amount in Switzerland in recent years. The public agencies now have important transaction data on the registration and the mandatory inspection of cars that no other stakeholder can provide. Here, the Cardossier case is similar to the case of land registries in more developed countries (e.g., Themistocleous 2018, Ziolkowski et al. 2018). It just does not make sense to duplicate efforts if high quality registries already exist; however, it makes a lot of sense to "wrap" a blockchain "around" 
the registries, allowing distributed access, and to collect additional data in this blockchain.

c) Source of trust: Swiss citizens may not like the car registration authorities, but they trust them in several senses. They trust that a system supported by the authorities is not a passing fad, but there to stay; they trust that such a system at least fulfills the quality standard they are used to in other E-Government applications; and they trust that such a system complies to law and regulation. This trust is particularly important with such a hyped and little-understood new technology as blockchains. This observation is in line with reports from traditional data collaboratives (Klievink et al. 2018). In this case we can shed more light on what exactly is meant by trust here: It is institutional trust (Auinger \&Riedl 2018) that is transferred to a platform. If there are no trustworthy institutions participating in a platform, it is difficult to launch it. In a similar vein, companies are more likely to join if public agencies commit to it. For private companies, the participation of relevant public agencies is a signal of its trustworthiness and its potential longevity.

d) Guarantor of data quality: Data quality has been a major issue in traditional data collaboratives (Klievink et al. 2018). While blockchains have mechanisms to ensure that data is not changed after it has been entered, they cannot guarantee the quality of the data when it is initially entered. Here, other mechanisms have to be used: Government registries have specialized procedures and regulations to assure data quality. Thus, in many developed countries, blockchain systems can either import their data or use them as an external 'oracle' (Xu et al. 2016). This role as a trusted data source has been 
primarily discussed in blockchain literature on land-registers (Themistocleous 2018; Ziolkowksi et al. 2018; Benbunan-Fich \& Castellanos 2018), health (Gordon \& Catalini 2018), or in academic certification (Gräther et al. 2018). But the Cardossier case shows that the role of public agencies goes even further: Public agencies can use their power to insist on and enforce data quality in a blockchain if it relies on the blockchain-based data for its internal work. The immutability of data entries into blockchain platforms strengthens the ability to check whether data has been altered.

e) User of data: The public sector has a lot of experience in collecting information it is legally required to receive. However, it is less experienced in exchanging digital data with other stakeholders in an ecosystem. Reasons for this are the limitations set by data protection laws, a lack of entrepreneurial spirit, and the limitations of sometimes outdated IT infrastructures and processes. The case of the Cardossier shows that public institutions, as a user of data, can benefit from a shared blockchain platform in three ways:

1. They can use the platform to integrate with other stakeholders and receive more data of high quality. This is particularly the case if they are at the end of an information chain and have to rely on secondary data (in this case data provided to the public administration by the car owners instead of the car importers).

2. A blockchain platform can be regarded as a distributed database with very finegranular access control and usage tracking. This allows both private partners and the public agencies to have much more detailed access to data and enables the exchange of data on a level that was not previously possible because the necessary strict regulations and data protection laws could not be implemented. 
They may even shift to an "optimistic access control", following the Estonia example ${ }^{7}:$ Here, many actors in the health ecosystem have access to the data, but the access is registered and can be challenged if necessary.

3. The public agencies can run analyses on a data set exceeding their own data resources. A self-sovereign data scheme integrated into the Cardossier platform ensures compliance with regulation and data law.

f) Incentive for making goods public: In many cases, the first five roles provide strong incentives to include public agencies in blockchain Consortia. Thus, it is no surprise that in many blockchain consortia the public agencies take over (or are lured into, as in the Cardossier project) the platform orchestrator role (e.g., in land registries (Ziolkowski et al. 2018)). But their participation comes at a cost for the private agencies: In Switzerland, there is a requirement in the Swiss constitution to treat all equally; thus, public agencies can only participate in blockchain consortia that are open to all Swiss stakeholders and this is best implemented in a non-profit association. The case of the Cardossier shows that the participation of public agencies in blockchain consortia in many senses 'socializes' blockchain platforms (i.e., makes them a public good). While this may have the additional benefit of taming the 'wild west' methods characterizing many markets for digital goods, it may also remove the incentives to participate in creating and running a joint platform. Architecture design (in the case of the Cardossier: allowing private DApps on a consortium blockchain) and governance design have to counter this threat.

\footnotetext{
${ }^{7}$ https://nortal.com/blog/blockchain-healthcare-estonia/
} 
Thus, blockchain platforms allow new ways to create suitable compromises between the diverging public and private interests discussed in the literature (see Susha et al. 2018).

The combination of these six roles explains why public agencies are not just "nice-tohave" partners in blockchain platforms, but rather they are key players. They are maybe even more powerful in this case than in the cases discussed in previous literature (Susha et al. 2018): In the Cardossier project, they shaped the nature of the platform and became president over its non-profit core.

\section{Conclusions and Limitations}

There is a history of public-private partnerships in infrastructure development and maintenance as well as in IT infrastructure development and data sharing. Many regulatory, organizational, data, and social issues discussed in the literature also apply to blockchain consortia. So, what is novel in the case of the Cardossier? A first novelty is the nature of the Cardossier as a multisided platform, connecting public agencies, private companies from the car ecosystem, software companies, and private carowners. A second novelty is the distributed ledger it is built upon. It allows a more finegranular approach to data sharing and new ways of governance.

The Cardossier case offers public agencies a clear understanding of the role they play in blockchain consortia: They have a key role not only as a data provider and participant in important interorganizational processes, but also as a source of trust and a guarantor of data quality. Creating public goods by participating in a multisided platform may be a new approach to public governance. 
When the Cardossier project started, there were quite a few competing projects from private startup companies proposing ICOs. Many of them don't exist anymore. So blockchain startup companies can learn from the case of the Cardossier that it is advisable to closely study the ecosystem they are trying to change. If they ignore important public agencies, they will likely fail. If they involve important public agencies, the nature of their undertaking is changing: Startup companies will have to orchestrate an ecosystem that can benefit a lot from the participation of public agencies, but they will have to care about the special expectations of public agencies, i.e., the platform will be different than the centralized and powerful Google or Facebook. It will rather (at least partially) be a public good with distributed data and power.

Researchers can learn what it means to involve public agencies in blockchain platforms: Involving public agencies forces the platform to operate within a legal and social system. This is in contrast to the libertarian roots of the blockchain in Bitcoin (Nakamoto (2008). This makes consortium and platform governance both more difficult and easier: It makes them more difficult, because the legal and social system put constraints on what is acceptable, and it makes them easier, because the legal and social system allow ways to incentivize and control the behavior of the actors.

However, this research comes with limitations. We study just one case in detail, and this case is situated within the specific legal and social system of Switzerland. It allowed to 
make the first steps without changing laws ${ }^{8}$. Other countries with different legislation may not offer the same opportunities for the involvement of public agencies. For example, in the US, much car-related data is published by government agencies and privacy legislation is less strict. Therefore, the private company Carfax, can offer some of the information packages to the car owners that the Cardossier strives to provide. Thus, there is ample opportunity for researchers to study how public-private consortia collaborate to create a joint platform using blockchains. Furthermore, the empirical basis of this study is sub-optimal in the sense that many observations cannot be systematically traced back. This is a compromise engaged scholars have to make in such a sensitive environment, but we would wish for more systematic research validating our observations. And finally, the Cardossier platform is not yet live. Proof-of-concept prototypes have been developed, proof-of-value has been demonstrated for many stakeholders, and we made a first successful step to proof-of-use by creating the Cardossier Association as a hub for a self-sustaining community of users. Go-live is scheduled for 2020. We are looking forward to further insights in the research journey.

\section{Acknowledgements}

The Cardossier project is a joint effort of AdNovum, AMAG Import, AXA Winterthur, Mobility, the Road Traffic Authorities of the Canton of Aargau, the Lucerne University of Applied Sciences and Arts, and the University of Zurich. I am grateful for the input that all partners gave; without it, the paper would not have been possible. I particularly thank

\footnotetext{
${ }^{8}$ But this will be necessary if all potentials for the Cardossier are to be reaped. For example, a law requiring the use of the Cardossier for registration would immediately guarantee widespread usage.
} 
my PhD students Liudmila Zavolokina, Rafael Ziolkowski, and Ingrid Bauer for contributing to the content of this paper. This research has been funded by Innosuisse under the project name "Blockchain Car Dossier".

\section{Literature}

Abraham, A. (2017): Self-Sovereign Identity - Whitepaper about the Concept of SelfSovereign Identity including its Potential. Retrieved from https://www.egiz.gv.at/files/download/Self-Sovereign-Identity-Whitepaper.pdf Akerlof, G. A. (1978). The market for "lemons": Quality uncertainty and the market mechanism. In The Quarterly Journal of Economics, Vol. 84, No. 3. (Aug, 1970), pp. $488-500$

Albrecht, S., Reichert, S., Schmid, J., Strüker, J., Neumann, D., \& Fridgen, G. (2018, January). Dynamics of blockchain implementation-a case study from the energy sector. Proceedings of the $51^{\text {st }}$ Annual Hawaii International Conference on System Sciences, pp. 3527-3536. https://doi.org/10.24251/HICSS.2018.446

Auinger, A., \& Riedl, R. (2018). Blockchain and Trust: Refuting Some Widely-held Misconceptions. Proceedings of the $39^{\text {th }}$ International Conference on Information Systems. San Francisco, CA, USA.

Bauer, I., Zavolokina, L., Leisibach, F., \& Schwabe, G. (2019, January). Exploring Blockchain Value Creation: The Case of the Car Ecosystem. Proceedings of the 52nd Annual Hawaii International Conference on System Sciences, pp. 6865-6874. https://doi.org/10.24251/HICSS.2019.822 
Bauer, I., Zavolokina, L., \& Schwabe, G. (2019). Is there a market for trusted car data? Electronic Markets. https://doi.org/10.1007/s12525-019-00368-5

Beck, R., Müller-Bloch, C., \& King, J. L. (2018). Governance in the blockchain economy: A framework and research agenda. Journal of the Association for Information Systems, 19(10), 1020-1034.

Benbunan-Fich, R., \& Castellanos, A. (2018). Digitization of Land Records: From Paper to Blockchain. Proceedings of the $39^{\text {th }}$ International Conference on Information Systems. San Francisco, CA, USA.

Briggs, R. O., Böhmann, T., Schwabe, G., \& Tuunanen, T. (2019). Advancing Design Science Research with Solution-based Probing. Proceedings of the 52nd Annual Hawaii International Conference on System Sciences, pp. 5725-5734. https://doi.org/10.24251/HICSS.2019.691

Chanson, M., Bogner, A., Bilgeri, D., Fleisch, E., \& Wortmann, F. (2019). PrivacyPreserving Data Certification in the Internet of Things: Leveraging Blockchain Technology to Protect Sensor Data. Journal of the Association for Information Systems, 20(9). https://doi.org/10.3929/ethz-b-000331556

Ciriello, R. F., Beck, R., \& Thatcher, J. (2018). The Paradoxical Effects of Blockchain Technology on Social Networking Practices. Proceedings of the $39^{\text {th }}$ International Conference on Information Systems. San Francisco, CA, USA.

Fridgen, G., Guggenmoos, F., Lockl, J., Rieger, A., \& Schweizer, A. (2018). Developing an Evaluation Framework for Blockchain in the Public Sector: The Example of the German Asylum Process. Proceedings of 1st ERCIM Blockchain Workshop 2018. European Society for Socially Embedded Technologies (EUSSET). https://doi.org/10.18420/blockchain2018_10 
Glaser, F., Hawlitschek, F., \& Notheisen, B. (2019). Blockchain as a Platform. Business Transformation through Blockchain, 121-143. Palgrave Macmillan, Cham. https://doi.org/10.1007/978-3-319-98911-2_4

Gordon, W. J., \& Catalini, C. (2018). Blockchain technology for healthcare: facilitating the transition to patient-driven interoperability. Computational and structural biotechnology journal, 16, 224-230. https://doi.org/10.1016/j.csbj.2018.06.003.

Gräther, W., Kolvenbach, S., Ruland, R., Schütte, J., Torres, C. F. \& Wendland, F. (2018). Blockchain for Education: Lifelong Learning Passport. In: W. Prinz \& P. Hoschka (Eds.), Proceedings of the 1st ERCIM Blockchain Workshop 2018, Reports of the European $\begin{array}{llll}\text { Society for Socially } & \text { Embedded }\end{array}$ https://dl.eusset.eu/handle/20.500.12015/3163

Hart, O. (2003), Incomplete Contracts and Public Ownership: Remarks, and an Application to Public-Private Partnerships*. The Economic Journal, 113: pp. 69-76. doi:10.1111/1468-0297.00119

Hodge, G. A., \& Greve, C. (2007). Public-Private Partnerships: An International Performance Review. Public Administration Review,67(3), pp. 545558. https://doi.org/10.1111/j.1540-6210.2007.00736.x

Hughes, T. P. (1993). Networks of power: electrification in Western society, 1880-1930. JHU Press. https://hdl.handle.net/2027/heb.00001

Kenney, M., \& Zysman, J. (2016). The rise of the platform economy. Issues in Science and Technology, 32(3), 61.

Klievink, B., Bharosa, N., \& Tan, Y. H. (2016). The collaborative realization of public values and business goals: Governance and infrastructure of public-private information platforms. Government Information Quarterly, 33(1), 67-79. 
Klievink, B., van der Voort, H., \& Veeneman, W. (2018). Creating value through data collaboratives. Information Polity, 23(4), pp. 379-397. https://doi.org/10.3233/IP180070

Mathiassen, L., \& Nielsen, P. A. (2008). Engaged scholarship in IS research. Scandinavian Journal of Information Systems, 20(2), 1.

Miscione, G., Klein, S., Schwabe, G., Goerke, T., Ziolkowski, R. (2019). Hanseatic Governance: Understanding Blockchain as Organizational Technology. Proceedings of the $40^{\text {th }}$ International Conference on Information Systems. Munich, Germany.

Miscione, G., Ziolkowski, R., Zavolokina, L., \& Schwabe, G. (2018). Tribal Governance: The Business of Blockchain Authentication. Proceedings of the 51st Annual Hawaii International Conference on System Sciences, pp. 4484-4493. https://doi.org/10.24251/HICSS.2018.566

Nakamoto, S. (2008). Bitcoin: A peer-to-peer electronic cash system. Retrieved from https://bitcoin.org/bitcoin.pdf

Notheisen, B., Cholewa, J. B., \& Shanmugam, A. P. (2017). Trading real-world assets on blockchain. Business \& Information Systems Engineering, 59(6), 425-440.

Novotny, P., Zhang, Q., Hull, R., Baset, S., Laredo, J., Vaculin, R., Ford, D. L., Dillenberger, D. N. (2018). Permissioned blockchain technologies for academic publishing. Information Services \& Use, 38(3), pp. 159-171. https://doi.org/10.3233/isu-180020

Nunamaker Jr, J. F., Briggs, R. O., Derrick, D. C., \& Schwabe, G. (2015). The last research mile: Achieving both rigor and relevance in information systems research. Journal of management information systems, 32(3), 10-47. https://doi.org/10.1080/07421222.2015.1094961 
Oliveira, L., Zavolokina, L., Bauer, I., \& Schwabe, G. (2018). To Token or not to Token: Tools for Understanding Blockchain Tokens. Proceedings of the $39^{\text {th }}$ International Conference on Information Systems. San Francisco, CA, USA. https://doi.org/10.5167/uzh-157908

$\varnothing$ Ines, S., Ubacht, J., \& Janssen, M. (2017). Blockchain in government: Benefits and implications of distributed ledger technology for information sharing. Government Information Quarterly, 34 (3), 355-364. https://doi.org/10.1016/j.giq.2017.09.007

Schmidt, P. (2015). Certificates, reputation, and the blockchain. Retrieved from https://medium.com/mit-media-lab/certificates-reputation-and-the-blockchainaee03622426f

Sein, M., Henfridsson, O., Purao, S., Rossi, M., \& Lindgren, R. (2011). Action design research. MIS Quarterly Vol. 35 (1) pp. 37-56.

Susha, I., Grönlund, Å., \& Van Tulder, R. (2018). Data driven social partnerships: Exploring an emergent trend in search of research challenges and questions. Government Information Quarterly, 36(1), pp. 112-128. https://doi.org/10.1016/j.giq.2018.11.002

Tapscott, D., \& Tapscott, A. (2016). Blockchain revolution: how the technology behind bitcoin is changing money, business, and the world. Penguin.

Themistocleous, M. (2018): Blockchain Technology and Land Registry. The Cyprus review 30 (2), 195 - 202.

Truong, N. B., Um, T. W., Zhou, B., \& Lee, G. M. (2018, May). Strengthening the blockchain-based internet of value with trust. IEEE International Conference on Communications. https://doi.org/10.1109/icc.2018.8423014 
Vazirani, A. A., O'Donoghue, O., Brindley, D., \& Meinert, E. (2019). Implementing Blockchains for Efficient Health Care: Systematic Review. Journal of medical Internet research, 21(2):e12439. https://doi.org/10.2196/12439

Verhulst, S., \& Sangokoya, D. (2015). Data collaboratives: Exchanging data to improve people's lives. Retrieved from https://medium.com/@sverhulst/data-collaborativesexchanging-data-to-improve-people-s-lives-d0fcfc1bdd9a

Xu, X., Pautasso, C., Zhu, L., Gramoli, V., Ponomarev, A., Tran, A. B., \& Chen, S. (2016, April). The blockchain as a software connector. 13th Working IEEE/IFIP Conference on Software Architecture (WICSA), pp. 182-191. https://doi.org/ 10.1109/WICSA.2016.21

Zavolokina, L., Miscione, G., \& Schwabe, G. (2019, January). Buyers of Lemons: Addressing Buyers' Needs in the Market for Lemons with Blockchain Technology. Proceedings of the 52nd Annual Hawaii International Conference on System Sciences Sciences, 1844-1853. https://doi.org/ 10.24251/HICSS.2019.223

Zavolokina, L., Spychiger, F., Tessone, C. J., \& Schwabe, G. (2018). Incentivizing Data Quality in Blockchains for Inter-Organizational Networks "Learning from the Digital Car Dossier. Proceedings of the 39th International Conference on Information Systems. San Francisco, CA, USA. https://doi.org/10.5167/uzh-157909

Zavolokina, L., \& Bauer, I. (2018). Simulation-based design for exploring and evaluating blockchain applications. Treo talk at the $39^{\text {th }}$ International Conference on Information Systems. San Francisco, CA, USA.

Zhang, A., \& Lin, X. (2018). Towards secure and privacy-preserving data sharing in ehealth systems via consortium blockchain. Journal of medical systems, 42(8), 140. https://doi.org/10.1007/s10916-018-0995-5 
Ziolkowski, R., Miscione, G., \& Schwabe, G. (2018). Consensus through Blockchains: Exploring Governance across inter-organizational Settings. Proceedings of the $39^{\text {th }}$ International Conference on Information Systems. San Francisco, CA, USA. https://doi.org/10.5167/uzh-160378

Ziolkowski, R., Parangi, G., Miscione, G., \& Schwabe, G. (2019). Examining Gentle Rivalry: Decision-Making in Blockchain Systems. Proceedings of the 52nd Annual Hawaii International Conference on System Sciences Sciences, pp. 4535-4544. https://doi.org/ 10.24251/HICSS.2019.550

Zwitter, A., \& Boisse-Despiaux, M. (2018). Blockchain for humanitarian action and development aid. Journal of International Humanitarian Action, 3(1), 16. https://doi.org/10.1186/s41018-018-0044-5 